\title{
Occupancy Dependency of Maxwell-Stefan Diffusivities in Ordered Crystalline Microporous Materials
}

\author{
Rajamani Krishna*๑
}

Van't Hoff Institute for Molecular Sciences, University of Amsterdam, Science Park 904, 1098 XH Amsterdam, The Netherlands

\author{
Supporting Information
}

ABSTRACT: Molecular dynamics simulation data for a variety of binary guest mixtures $\left(\mathrm{H}_{2} / \mathrm{CO}_{2}, \mathrm{Ne} / \mathrm{CO}_{2}, \mathrm{CH}_{4} / \mathrm{CO}_{2}, \mathrm{CO}_{2} / \mathrm{N}_{2}, \mathrm{H}_{2} / \mathrm{CH}_{4}, \mathrm{H}_{2} / \mathrm{Ar}\right.$, $\mathrm{CH}_{4} / \mathrm{Ar}, \mathrm{Ar} / \mathrm{Kr}, \mathrm{Ne} / \mathrm{Ar}, \mathrm{CH}_{4} / \mathrm{C}_{2} \mathrm{H}_{6}, \mathrm{CH}_{4} / \mathrm{C}_{3} \mathrm{H}_{8}, \mathrm{C}_{2} \mathrm{H}_{6} \mathrm{C}_{3} \mathrm{H}_{8}, \mathrm{CH}_{4} / n \mathrm{C}_{4} \mathrm{H}_{10}$, and $\mathrm{CH}_{4} / n \mathrm{C}_{5} \mathrm{H}_{11}$ ) in zeolites (MFI, BEA, ISV, FAU (all-silica), $\mathrm{NaY}, \mathrm{NaX}$, LTA, CHA, DDR) and metal-organic frameworks (MOFs) (IRMOF-1, CuBTC, MgMOF-74) show that the Maxwell-Stefan (M-S) diffusivities, $\bigoplus_{1}, \bigoplus_{2}, \bigoplus_{12}$, are strongly dependent on the molar loadings. The main aim of this article is to develop a fundamental basis for describing the loading dependence of $\mathrm{M}-\mathrm{S}$ diffusivities. Using the ideal adsorbed solution theory, a thermodynamically rigorous definition of the occupancy, $\theta$, is derived; this serves as a convenient proxy for the spreading pressure, $\pi$, and provides the correct metric to describe the loading dependence of diffusivities. Configurational-bias Monte Carlo simulations of the unary adsorption

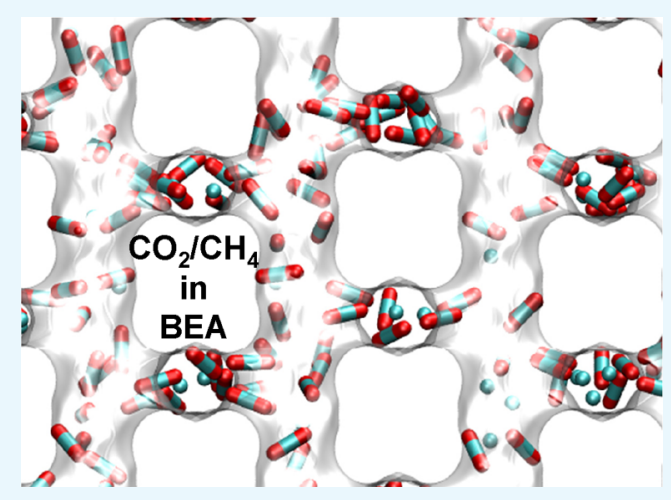
isotherms are used for the calculation of the spreading pressure, $\pi$, and occupancy, $\theta$. The $\mathrm{M}-\mathrm{S}$ diffusivity, $\bigoplus_{i}$, of either constituent in binary mixtures has the same value as that for unary diffusion, provided the comparison is made at the same $\theta$. Furthermore, compared at the same value of $\theta$, the $M-S$ diffusivity $\bigoplus_{i}$ of any component in a mixture does not depend on it partner species. The $\bigoplus_{i}$ versus $\theta$ dependence is amenable to simple interpretation using lattice-models. The degree of correlations, defined by the ratio $\bigoplus_{1} / \bigoplus_{12}$, that characterizes mixture diffusion shows a linear increase with occupancy $\theta$, implying that correlations become increasingly important as pore saturation conditions are approached.

\section{INTRODUCTION}

Ordered crystalline microporous materials such as zeolites (alumino-silicates), metal-organic frameworks (MOFs), and zeolitic imidazolate frameworks have wide applications as catalysts, adsorbents, and as perm-selective layers in membrane separations. ${ }^{1-8}$ The design and development of catalytic and separation processes requires reliable and accurate models to describe intracrystalline diffusion of mixtures of guest molecules. $3,7,9$ Intracrystalline diffusion of reactants and products invariably exert a strong influence on the conversion and selectivity of catalyzed reactions. ${ }^{10-12}$ For mixture separations in a fixed-bed adsorber, intraparticle diffusion limitations cause distended breakthrough characteristics and usually lead to diminished separation effectiveness. ${ }^{13,14}$ Diffusional effects may become strong enough to over-ride the influence of mixture adsorption equilibrium and become the prime driver in fixed-bed separations. ${ }^{14-18}$ The selectivities in membrane separations are governed by a combination of mixture adsorption equilibrium and mixture diffusion characteristics. ${ }^{4,19-21}$

It is widely recognized that the most convenient and practical approach to modeling $n$-component mixture diffusion is to adopt the Maxwell-Stefan $(\mathrm{M}-\mathrm{S})$ formulation that relates the intracrystalline molar fluxes $N_{i}$ to the chemical potential gradients $6,7,9$

$$
\begin{aligned}
& -\rho \frac{q_{i}}{R T} \frac{\mathrm{d} \mu_{i}}{\mathrm{~d} z}=\sum_{\substack{j=1 \\
j \neq i}}^{n} \frac{x_{j} N_{i}-x_{i} N_{j}}{\bigoplus_{i j}}+\frac{N_{i}}{\bigoplus_{i}} \\
& i=1,2, \ldots, n
\end{aligned}
$$

where $R$ is the gas constant $\left(=8.314 \mathrm{~J} \mathrm{~mol}^{-1} \mathrm{~K}^{-1}\right), \rho$ represents the framework density of the microporous crystalline material, and the component loadings $q_{i}$ are defined in terms of moles per $\mathrm{kg}$ of framework. The $x_{i}$ in eq 1 are the component mole fractions of the adsorbed phase within the micropores

$$
\begin{gathered}
x_{i}=q_{i} / q_{t} ; \quad q_{t}=q_{1}+q_{2}+\ldots+q_{n} ; \\
i=1,2, \ldots, n
\end{gathered}
$$

The $\bigoplus_{i}$ characterize species $i-$ wall interactions in the broadest sense. The $\bigoplus_{i j}$ are exchange coefficients representing interaction between components $i$ with component $j$. At the molecular level, the $\bigoplus_{i j}$ reflect how the facility for transport of species $i$ correlates with that of species $j$. Conformity with the Onsager reciprocal relations demands the symmetry constraint

Received: September 20, 2018

Accepted: November 6, 2018

Published: November 19, 2018 

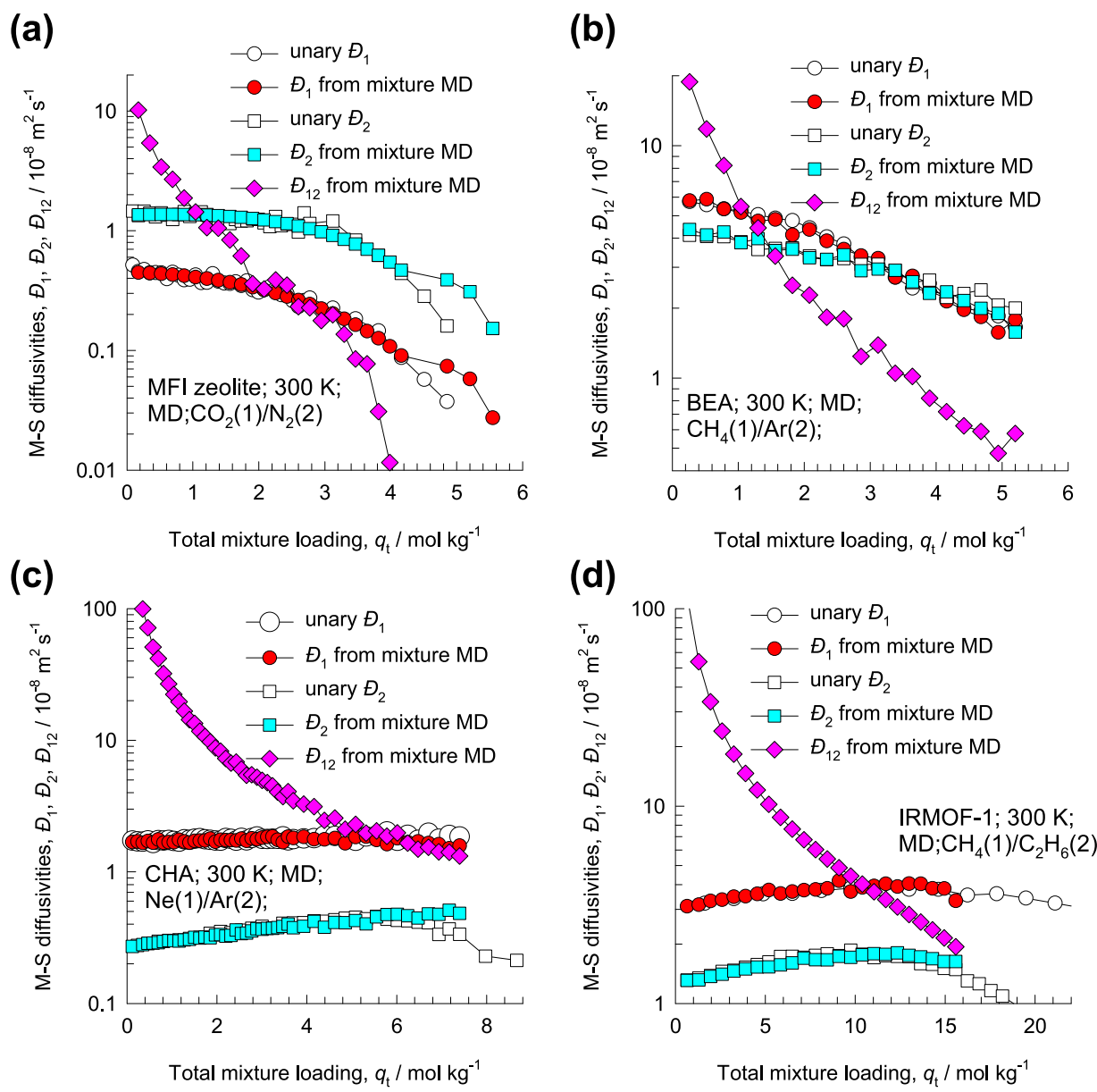

Figure 1. M-S diffusivities $\bigoplus_{1}, \bigoplus_{2}$, and $\bigoplus_{12}$, backed out from MD-simulated values of $\Lambda_{i j}$, for equimolar $\left(q_{1}=q_{2}\right)$ binary mixtures: $(\mathrm{a}) \mathrm{CO}_{2}(1) /$ $\mathrm{N}_{2}(2)$ in MFI, (b) $\mathrm{CH}_{4}(1) / \mathrm{Ar}(2)$ in BEA, (c) $\mathrm{Ne}(1) / \mathrm{Ar}(2)$ in CHA, and (d) $\mathrm{CH}_{4}(1) / \mathrm{C}_{2} \mathrm{H}_{6}(2)$ in IRMOF-1. The $x$-axis is the total mixture loading $q_{\mathrm{t}}=q_{1}+q_{2}$. Also plotted are the $\mathrm{MD}$ simulation data for the corresponding unary diffusivities.

$$
\mathrm{Ð}_{i j}=\mathrm{Ð}_{j i}
$$

Specifically, for a binary mixture, that is $n=2$, the $M-S$ eq 1 can be re-written to evaluate the fluxes $N_{i}$ explicitly by defining a matrix $[\Lambda]$

$$
N_{i}=-\rho \sum_{j=1}^{n} \Lambda_{i j} \frac{q_{j}}{R T} \frac{\mathrm{d} \mu_{j}}{\mathrm{~d} z} ; \quad i=1,2, \ldots, n
$$

Combining eq 1 with 4 we derive the following explicit expression for calculation of the elements of the $2 \times 2$ dimensional square matrix $[\Lambda]$

$$
\begin{aligned}
& {[\Lambda]=\left[\begin{array}{ll}
\frac{1}{\mathrm{Ð}_{1}}+\frac{x_{2}}{\mathrm{Ð}_{12}} & -\frac{x_{1}}{\mathrm{Ð}_{12}} \\
-\frac{x_{2}}{\mathrm{Ð}_{12}} & \frac{1}{\mathrm{Ð}_{2}}+\frac{x_{1}}{\mathrm{Ð}_{12}}
\end{array}\right]^{-1}}
\end{aligned}
$$

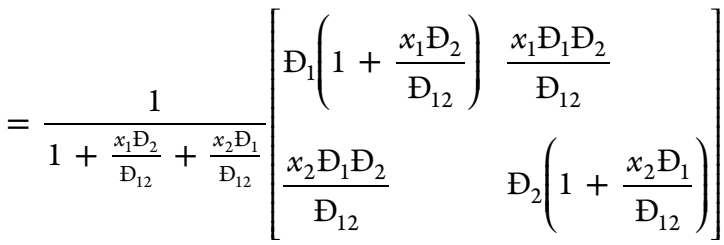

The ratios $\bigoplus_{1} / \bigoplus_{12}$, and $\bigoplus_{2} / \bigoplus_{12}$ quantify the degrees of correlation. The magnitude of $\Xi_{1}$, relative to that of $\bigoplus_{12}$, determines the extent to which the flux of species 1 is influenced by the chemical potential gradient of species 2 . The larger the degree of correlation, $\bigoplus_{1} / \bigoplus_{12}$, the stronger is the influence of diffusional "coupling". Generally speaking, the more-strongly-adsorbed-tardier partner species will have the effect of slowing down the less-strongly-adsorbed-more-mobile partner in the mixture.

The elements of $[\Lambda]$ cannot be determined directly from experimental measurements. However, $\Lambda_{i j}$ are directly accessible from molecular dynamics (MD) simulations ${ }^{22}$ by monitoring the individual molecular displacements

$$
\begin{aligned}
\Lambda_{i j}= & \frac{1}{2} \lim _{\Delta t \rightarrow \infty} \frac{1}{n_{j}} \frac{1}{\Delta t}\left\langle\left(\sum_{l=1}^{n_{i}}\left(\mathbf{r}_{l, i}(t+\Delta t)-\mathbf{r}_{l, i}(t)\right)\right)\right. \\
& \left.\times\left(\sum_{k=1}^{n_{j}}\left(\mathbf{r}_{k, j}(t+\Delta t)-\mathbf{r}_{k, j}(t)\right)\right)\right\rangle
\end{aligned}
$$

In this expression, $n_{i}$ and $n_{j}$ represent the number of molecules of species $i$ and $j$, respectively, and $\mathbf{r}_{l, i}(t)$ is the position of molecule $l$ of species $i$ at any time $t$. The three M$S$ diffusivities $\bigoplus_{1}, \bigoplus_{2}$, and $\bigoplus_{12}$ can be backed out from the MD-simulated values of $\Lambda_{i j}$ for the binary mixture; detailed procedures are provided in the Supporting Information 
(a)

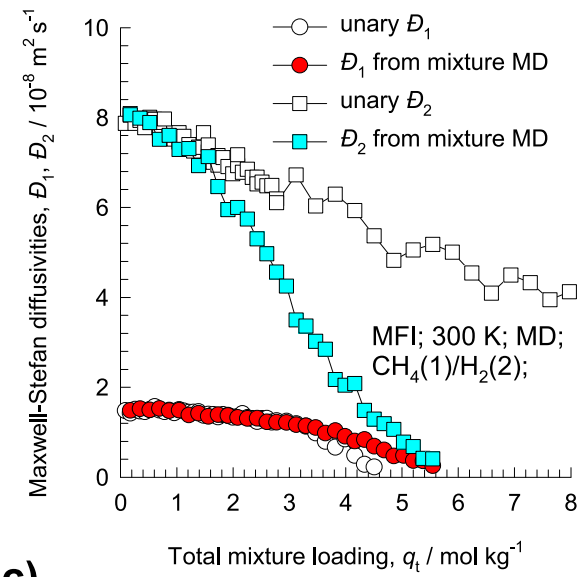

(c)

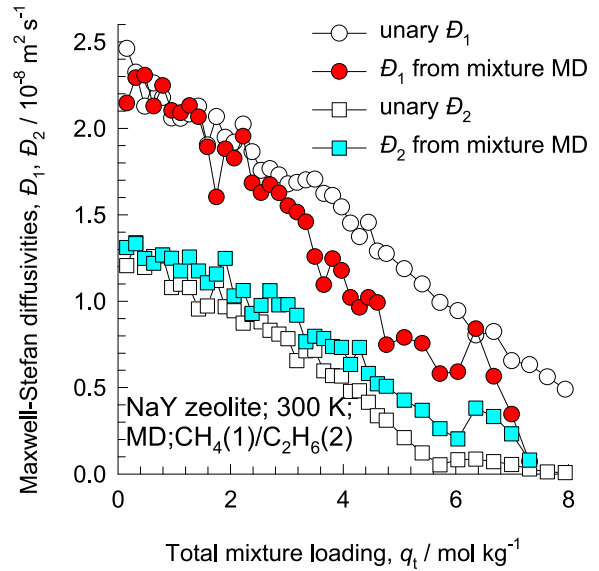

(e)

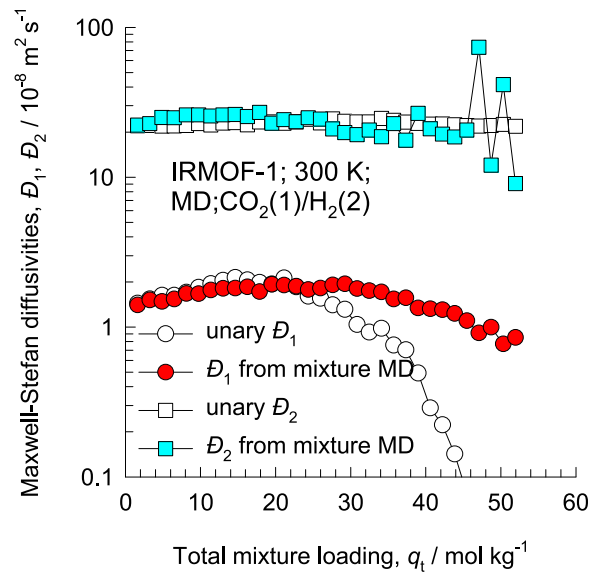

(b)

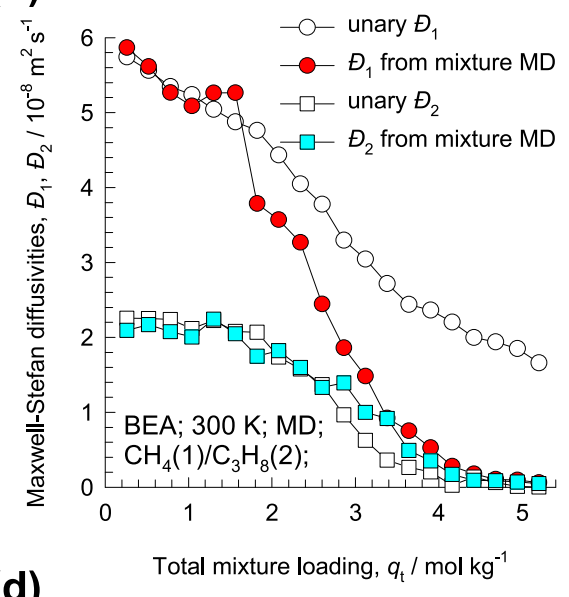

(d)

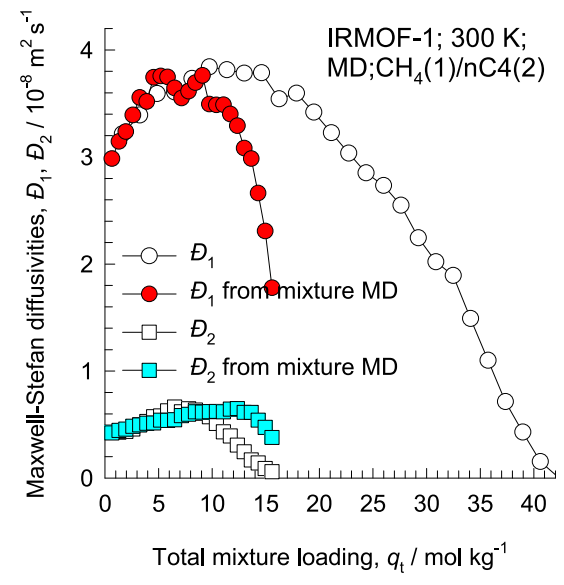

(f)

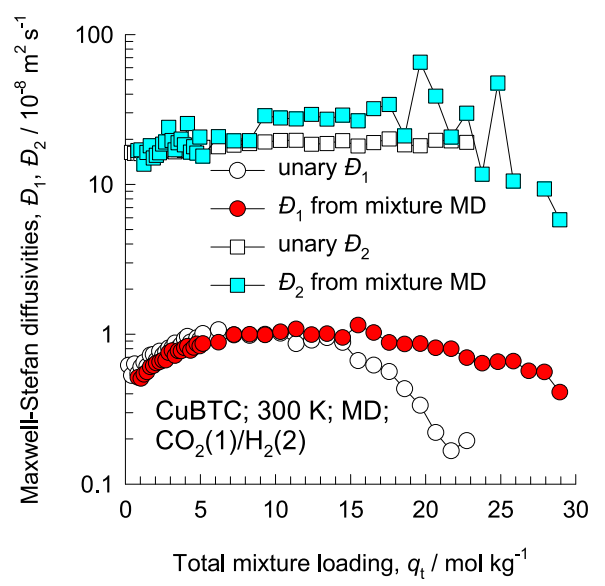

Figure 2. $M-S$ diffusivities $\bigoplus_{1}$ and $\bigoplus_{2}$, backed out from MD-simulated values of $\Lambda_{i i}$, for equimolar $\left(q_{1}=q_{2}\right)$ binary mixtures: $\left(\right.$ a) $\mathrm{CH}_{4}(1) / \mathrm{H}_{2}(2)$ in MFI, (b) $\mathrm{CH}_{4}(1) / \mathrm{C}_{3} \mathrm{H}_{8}(2)$ in BEA, (c) $\mathrm{CH}_{4}(1) / \mathrm{C}_{2} \mathrm{H}_{6}(2)$ in $\mathrm{NaY}$ zeolite, (d) $\mathrm{CH}_{4}(1) / n \mathrm{C}_{4} \mathrm{H}_{10}(2)$ in IRMOF-1, (e) $\mathrm{CO}_{2}(1) / \mathrm{H}_{2}(2)$ in IRMOF-1, and (f) $\mathrm{CO}_{2}(1) / \mathrm{H}_{2}(2)$ in CuBTC. The $x$-axis is the total mixture loading $q_{\mathrm{t}}=q_{1}+q_{2}$. Also plotted are the MD simulation data for the corresponding unary diffusivities.

accompanying this publication. As illustration, Figure 1 presents the $\mathrm{M}-\mathrm{S}$ diffusivities for four different mixture/ host combinations: $\mathrm{CO}_{2} / \mathrm{N}_{2}$ in $\mathrm{MFI}, \mathrm{CH}_{4} / \mathrm{Ar}$ in BEA, Ne/Ar in $\mathrm{CHA}$, and $\mathrm{CH}_{4} / \mathrm{C}_{2} \mathrm{H}_{6}$ in IRMOF-1. It is noteworthy that the $\mathrm{M}-\mathrm{S}$ diffusivities are not constant but vary with the total mixture loading $q_{\mathrm{t}}=q_{1}+q_{2}$.

Formally speaking, the $M-S$ eqs 1 and 4 serve only to define the $M-S$ diffusivities $\bigoplus_{1}, \bigoplus_{2}$, and $\bigoplus_{12}$; for practical applications, we need reliable procedures for estimation of these diffusivities. An important, persuasive advantage of the $M-S$ formulation is that the $M-S$ diffusivities $\bigoplus_{1}$ and $\bigoplus_{2}$ for mixture diffusion may be identified with the corresponding $\mathrm{M}-\mathrm{S}$ diffusivities for unary diffusion that are more easily accessible from either experiments or MD simulations. ${ }^{23}$ To test this hypothesis, the MD-simulated values of the unary diffusivities are also plotted in Figure 1. For the four sets, 
there is reasonably good agreement between the unary diffusivities and the corresponding values in the mixture.

For binary mixtures of guest constituents that have significantly large differences in saturation capacities, the agreement between the $\mathrm{M}-\mathrm{S}$ diffusivities in the mixture is not as good as portrayed in Figure 1, especially as pore saturation conditions are approached. This is evidenced by the data presented in Figure 2 for $\mathrm{CH}_{4} / \mathrm{H}_{2}$ in MFI, $\mathrm{CH}_{4} / \mathrm{C}_{3} \mathrm{H}_{8}$ in BEA, $\mathrm{CH}_{4} / \mathrm{C}_{2} \mathrm{H}_{6}$ in $\mathrm{NaY}$ zeolite, $\mathrm{CH}_{4} / n \mathrm{C}_{4} \mathrm{H}_{10}$ in IRMOF-1, $\mathrm{CO}_{2} /$ $\mathrm{H}_{2}$ in IRMOF-1, and $\mathrm{CO}_{2} / \mathrm{H}_{2}$ in CuBTC. The departures between two sets of data on the $\mathrm{M}-\mathrm{S}$ diffusivities $\bigoplus_{1}$ and $\bigoplus_{2}$ plotted in Figure 2 stem from the fact that the comparisons on the basis of total molar loadings are not based on a sound fundamental footing, as we shall demonstrate in this article.

This article has fourfold objectives. First, using the ideal adsorbed solution theory (IAST) of Myers and Prausnitz, ${ }^{24}$ we develop arguments to demonstrate that comparisons of the diffusivities in the mixture with the constituent unary diffusivities need to be based on equality of spreading pressures, and not the total molar loadings. Second, we derive an expression for the occupancy, $\theta$, as a function of the spreading pressure; the derived $\theta$ serves as a convenient and practical proxy for the spreading pressures, and is the appropriate parameter to be used as $x$-axes in Figures 1 and 2. The third objective is to show that unary $M-S$ diffusivities, $\bigoplus_{1}$ and $\bigoplus_{2}$, when compared at the same occupancy $\theta$ are in good agreement with those determined from the MD simulations for binary mixtures, not just for the data in Figures 1 and 2 but for a wide variety of guest mixtures $\left(\mathrm{H}_{2} /\right.$ $\mathrm{CO}_{2}, \mathrm{Ne} / \mathrm{CO}_{2}, \mathrm{CH}_{4} / \mathrm{CO}_{2}, \mathrm{CO}_{2} / \mathrm{N}_{2}, \mathrm{H}_{2} / \mathrm{CH}_{4}, \mathrm{H}_{2} / \mathrm{Ar}, \mathrm{CH}_{4} /$ $\mathrm{Ar}, \mathrm{Ar} / \mathrm{Kr}, \mathrm{Ne} / \mathrm{Ar}, \mathrm{CH}_{4} / \mathrm{C}_{2} \mathrm{H}_{6}, \mathrm{CH}_{4} / \mathrm{C}_{3} \mathrm{H}_{8}, \mathrm{C}_{2} \mathrm{H}_{6} \mathrm{C}_{3} \mathrm{H}_{8}, \mathrm{CH}_{4} /$ $n \mathrm{C}_{4} \mathrm{H}_{10}$, and $\mathrm{CH}_{4} / n \mathrm{C}_{5} \mathrm{H}_{11}$ ) in zeolites (MFI, BEA, ISV, FAU (all-silica), NaY, NaX, LTA, CHA, DDR) and MOFs (IRMOF-1, CuBTC, MgMOF-74). The fourth objective is to show that degrees of correlations, $\bigoplus_{1} / \bigoplus_{12}$, and $\bigoplus_{2} / \bigoplus_{12}$, are linearly dependent on the occupancy $\theta$.

The Supporting Information accompanying this publication provides (a) structural details for zeolites and MOFs considered and analyzed in this article, (b) configurationalbias Monte Carlo (CBMC) simulation methodology, ${ }^{23,25,26}$ (c) MD simulation methodology, ${ }^{23}$ (d) CBMC simulation data of the unary adsorption isotherms, along with dualLangmuir-Freundlich data fits, (e) detailed derivation of the IAST calculation procedures for the spreading pressure, and its proxy $\theta$, using the unary adsorption isotherms determined from CBMC simulations, (f) $\mathrm{MD}$ simulation data sets for unary and binary mixture diffusion for each mixture/host combination (a total of 70 data sets), and (g) procedures for estimation of the degrees of correlation for mixture diffusion.

\section{THERMODYNAMICS OF MIXTURE ADSORPTION}

The thermodynamics of mixture adsorption has an important bearing on the diffusion characteristics within microporous crystalline host materials because the guest constituent molecules exist entirely in the adsorbed phase. The Gibbs adsorption equation ${ }^{3}$ in differential form is ${ }^{27,28}$

$$
A \mathrm{~d} \pi=\sum_{i=1}^{n} q_{i} \mathrm{~d} \mu_{i}
$$

In eq $7, A$ represents the surface area per $\mathrm{kg}$ of framework, $q_{i}$ is the molar loading, $\mu_{i}$ is the molar chemical potential, and $\pi$ is the spreading pressure. (a)

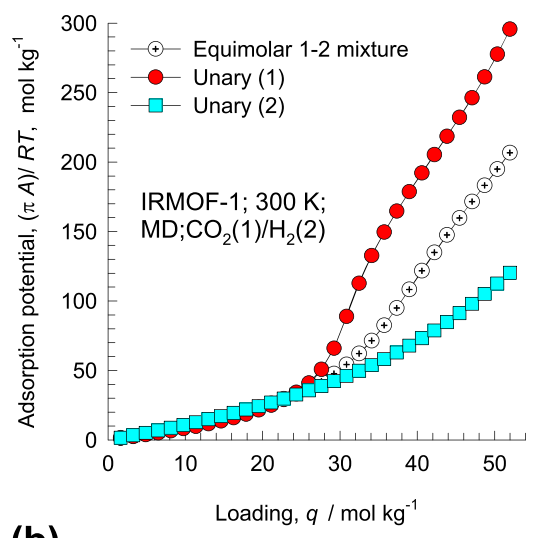

(b)

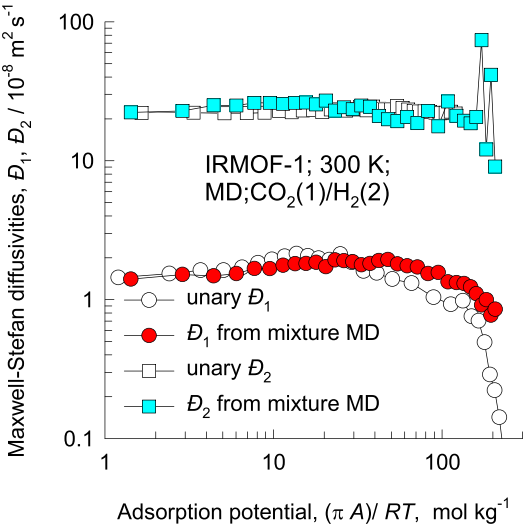

Figure 3. (a) Adsorption potential plotted as a function of the molar loading for equimolar $\left(q_{1}=q_{2}\right)$ binary $\mathrm{CO}_{2}(1) / \mathrm{H}_{2}(2)$ mixtures in IRMOF-1 at $300 \mathrm{~K}$. (b) Comparison of the unary M-S diffusivities $\bigoplus_{1}$ and $\bigoplus_{2}$ with those backed out from mixture MD simulations, plotted as a function of the adsorption potential.

At phase equilibrium, equating the component chemical potentials, $\mu_{i}$, in the adsorbed phase and in the bulk fluid phase mixture, we write

$$
\mathrm{d} \mu_{i}=R T \operatorname{dln} f_{i}
$$

Briefly, the basic equation of IAST of Myers and Prausnitz ${ }^{24}$ is the analogue of Raoult's law for vapor-liquid equilibrium, that is

$$
f_{i}=P_{i}^{0} x_{i} ; \quad i=1,2, \ldots, n
$$

where $x_{i}$ is the mole fraction in the adsorbed phase defined by eq 2 , and $P_{i}^{0}$ is the pressure for sorption of every component $i$, which yields the same spreading pressure, $\pi$, for each of the pure components, as that for the mixture

$$
\begin{aligned}
\frac{\pi A}{R T} & =\int_{0}^{P_{1}^{0}} \frac{q_{1}^{0}(f)}{f} \mathrm{~d} f=\int_{0}^{P_{2}^{0}} \frac{q_{2}^{0}(f)}{f} \mathrm{~d} f=\int_{0}^{P_{3}^{0}} \frac{q_{3}^{0}(f)}{f} \mathrm{~d} f \\
& =\ldots
\end{aligned}
$$

where $q_{i}^{0}(f)$ is the pure component adsorption isotherm. The units of $\frac{\pi A}{R T}$, also called the adsorption potential, ${ }^{29}$ are mol $\mathrm{kg}^{-1}$. Eq 10 suggests that the fundamentally correct procedure for comparing the unary $\mathrm{M}-\mathrm{S}$ diffusivities and those representing the mixture diffusion characteristics must be 
(a)

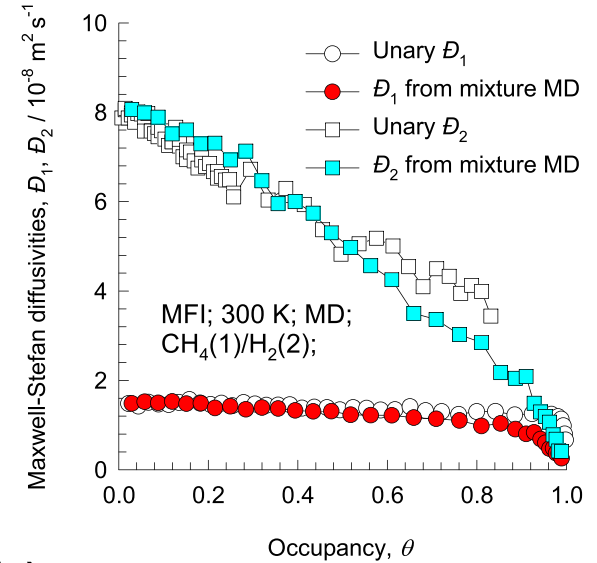

(c)

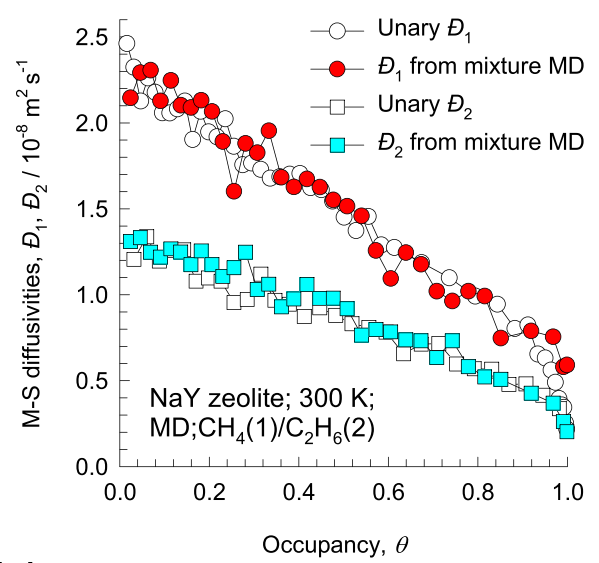

(e)

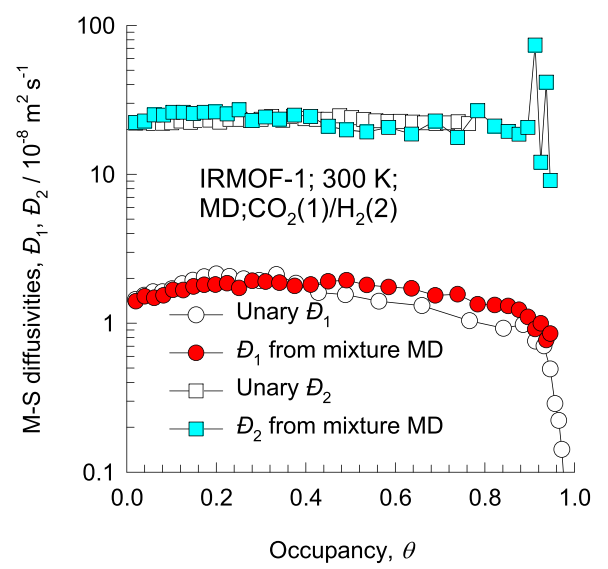

(b)

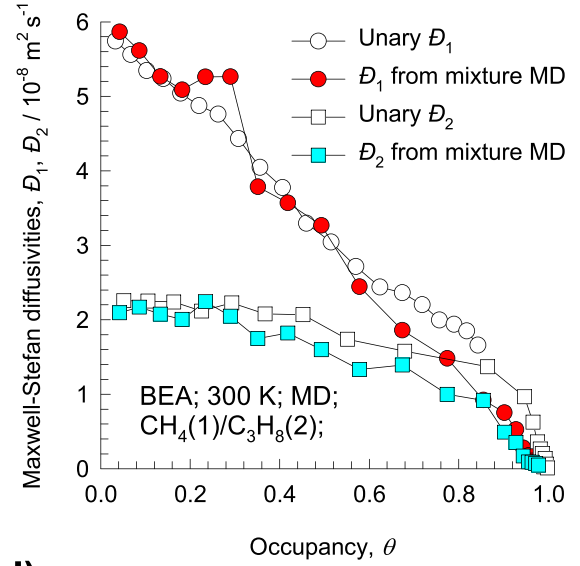

(d)

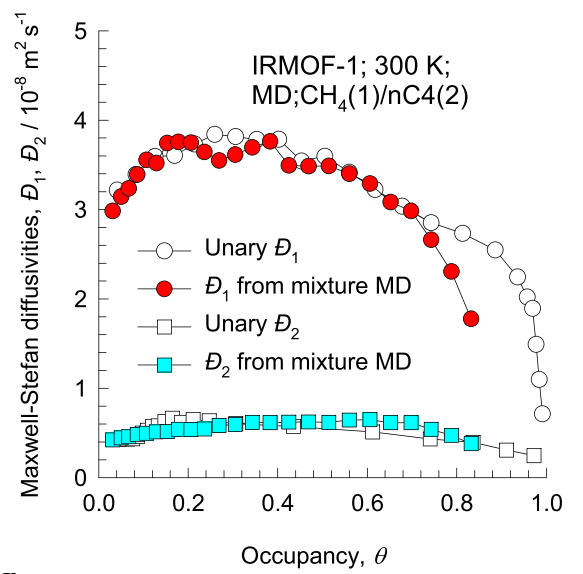

(f)

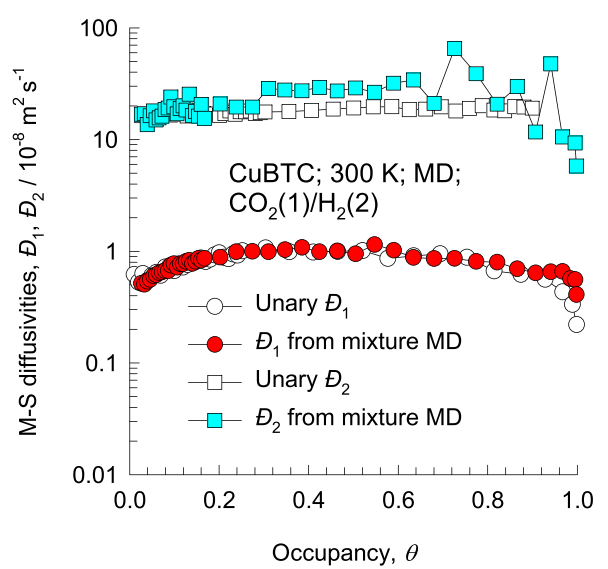

Figure 4. M-S diffusivities $\bigoplus_{1}$ and $\bigoplus_{2}$ backed out from MD-simulated values of $\Lambda_{i j}$, for equimolar $\left(q_{1}=q_{2}\right)$ binary mixtures: $($ a $) \mathrm{CH}_{4}(1) / \mathrm{H}_{2}(2)$ in MFI, (b) $\mathrm{CH}_{4}(1) / \mathrm{C}_{3} \mathrm{H}_{8}(2)$ in BEA, (c) $\mathrm{CH}_{4}(1) / \mathrm{C}_{2} \mathrm{H}_{6}(2)$ in $\mathrm{NaY}$ zeolite, (d) $\mathrm{CH}_{4}(1) / n \mathrm{C}_{4} \mathrm{H}_{10}(2)$ in IRMOF-1, (e) $\mathrm{CO}_{2}(1) / \mathrm{H}_{2}(2)$ in IRMOF-1, and (f) $\mathrm{CO}_{2}(1) / \mathrm{H}_{2}(2)$ in CuBTC. The $x$-axis is the occupancy $\theta$ defined by eq 15 .

done on the basis of equal adsorption potentials, that is a proxy for the spreading pressure.

For the simplest scenario in which the binary mixture is made up of components, whose unary isotherms are described by the 1-site Langmuir isotherm, with equal saturation capacities

$$
q_{i}^{0}(f)=q_{\text {sat }} \frac{b_{i} f}{1+b_{i} f} ; \quad i=1,2
$$

we derive the following expression for the mixture occupancy (detailed derivations are provided in the Supporting Information)

$$
\begin{aligned}
& \theta_{\text {Langmuir }}=\theta_{1}+\theta_{2}=\frac{q_{1}}{q_{\text {sat }}}+\frac{q_{2}}{q_{\text {sat }}}=1-\exp \left(-\frac{\pi A}{q_{\text {sat }} R T}\right) \\
& =\frac{b_{1} f_{1}+b_{2} f_{2}}{1+b_{1} f_{1}+b_{2} f_{2}}
\end{aligned}
$$


(a)

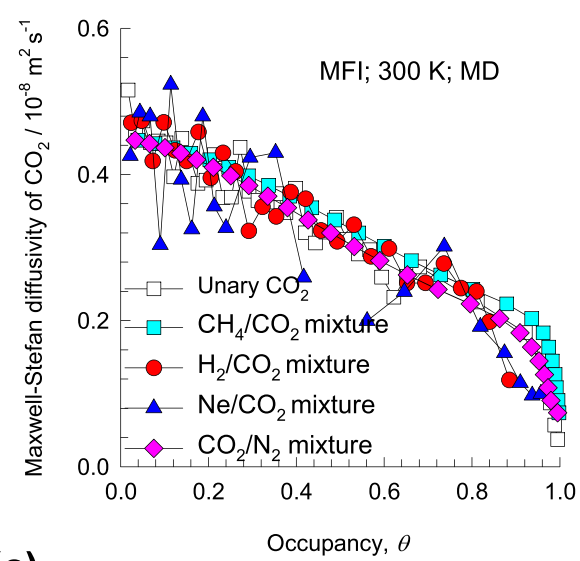

(c)

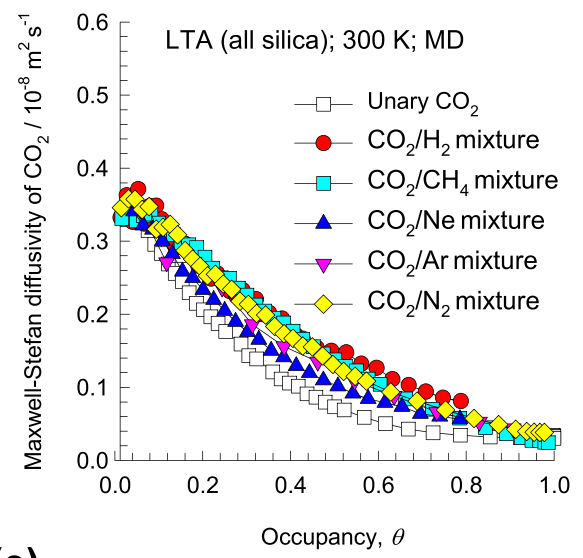

(e)

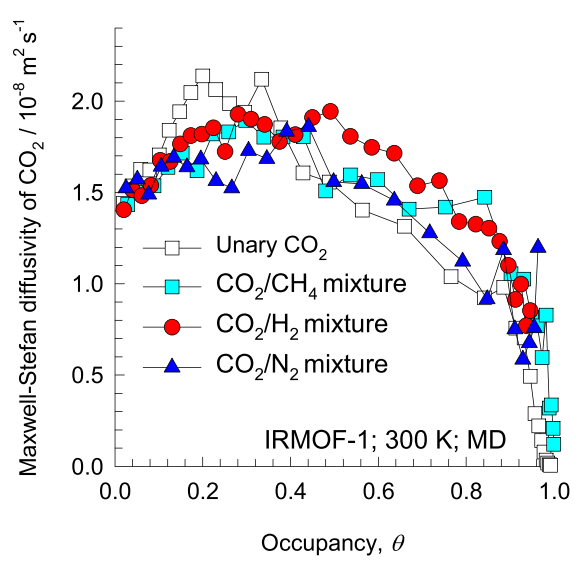

(b)

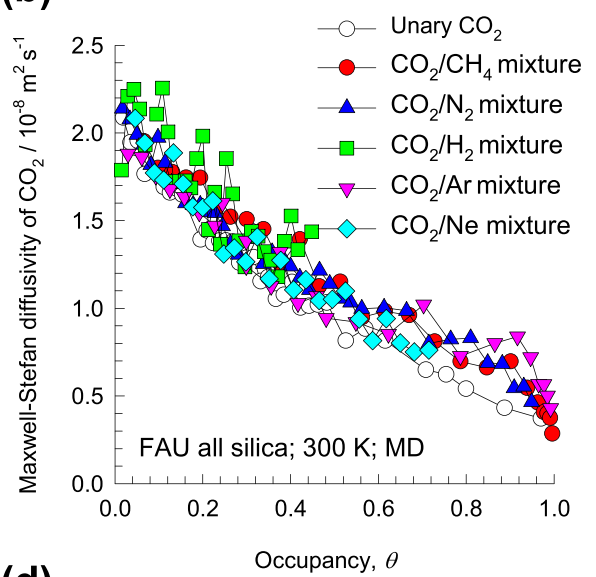

(d)

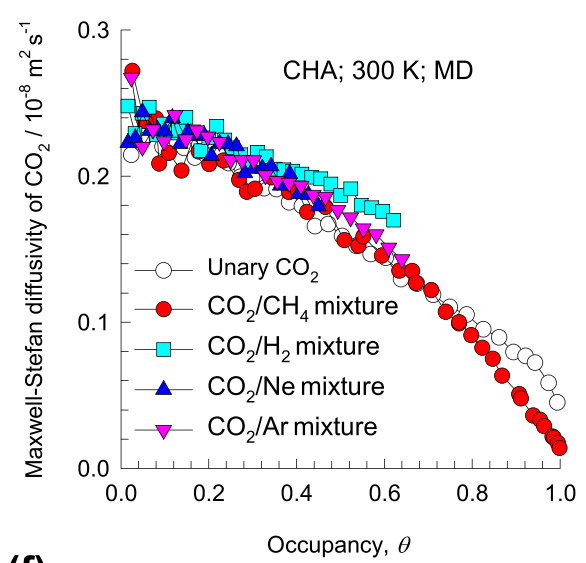

(f)

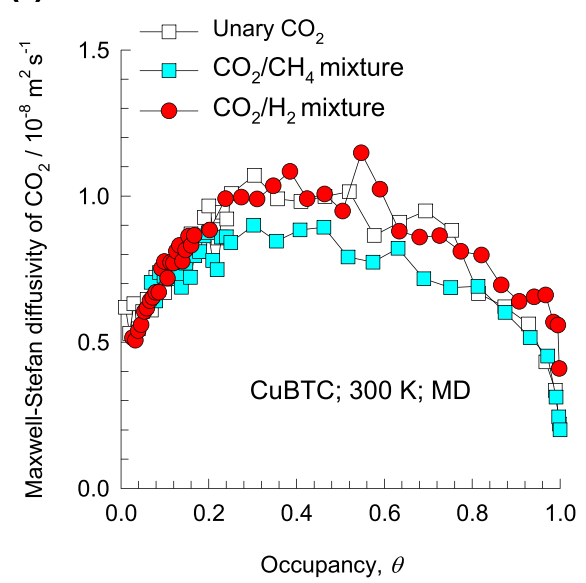

Figure 5. $\mathrm{M}-\mathrm{S}$ diffusivity, $\mathrm{D}_{i}$, of $\mathrm{CO}_{2}$-determined $\mathrm{MD}$ simulation data for diffusion of a variety of equimolar $\left(q_{1}=q_{2}\right)$ binary mixtures of $\mathrm{CO}_{2}$ and different partner species in (a) MFI, (b) FAU (all silica), (c) LTA, (d) CHA, (e) IRMOF-1, and (f) CuBTC. The $x$-axes represent the fractional $\theta$ defined by eq 15 . Also shown in open symbols are the MD simulations of $\bigoplus_{i}$, for unary $\mathrm{CO}_{2}$ diffusion.

For each of the guest/host combinations investigated in this study, CBMC simulations ${ }^{23,25,26,30}$ of the unary adsorption isotherms were performed in order to determine the unary isotherms. In every case, the unary isotherm characteristics required use of the more general dual-Langmuir-Freundlich model to describe the unary isotherms

$$
q^{0}(f)=q_{\mathrm{A}, \mathrm{sat}} \frac{b_{\mathrm{A}} f^{\nu \mathrm{A}}}{1+b_{\mathrm{A}} f^{\nu \mathrm{A}}}+q_{\mathrm{B}, \mathrm{sat}} \frac{b_{\mathrm{B}} f^{\nu \mathrm{B}}}{1+b_{\mathrm{B}} f^{\nu \mathrm{B}}} ; \quad i=1,2
$$

The dual-site Langmuir-Freundlich model fit parameters for every guest/host combination is tabulated in the Supporting Information accompanying this publication. Analytic integration of eq 10, in conjunction with eq 13, yields

$$
\begin{aligned}
\frac{\pi A}{R T} & =\int_{f=0}^{P_{i}^{0}} \frac{q^{0}(f)}{f} \mathrm{~d} f \\
& =\frac{q_{\mathrm{A}, \text { sat }}}{\nu_{\mathrm{A}}} \ln \left(1+b_{\mathrm{A}}\left(P_{i}^{0}\right)^{\nu_{\mathrm{A}}}\right)+\frac{q_{\mathrm{B}, \text { sat }}}{\nu_{\mathrm{B}}} \ln \left(1+b_{\mathrm{B}}\left(P_{i}^{0}\right)^{\nu_{\mathrm{B}}}\right)
\end{aligned}
$$


(a)

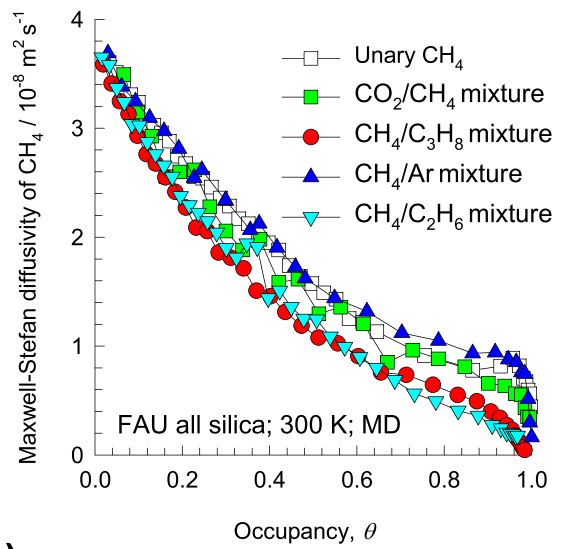

(c)

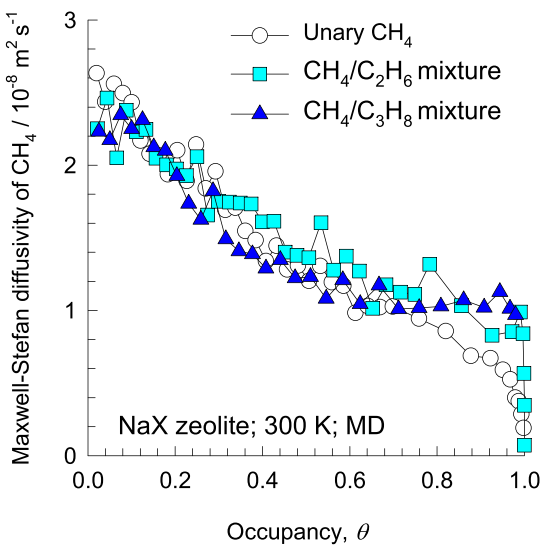

(e)

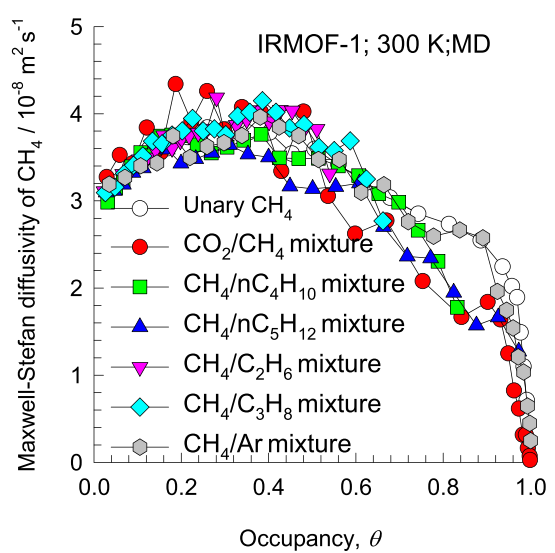

(b)

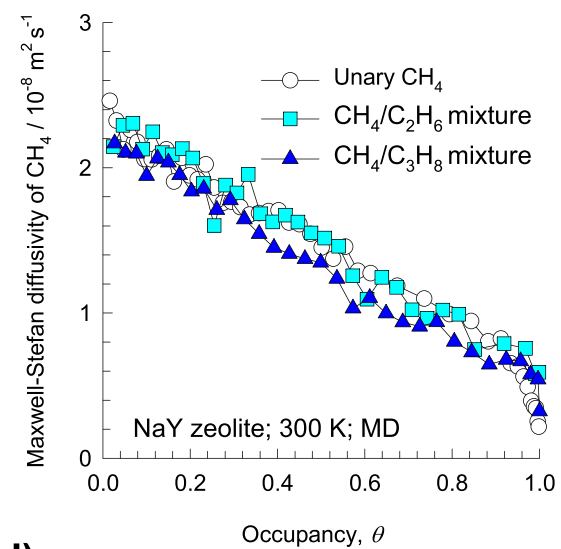

(d)

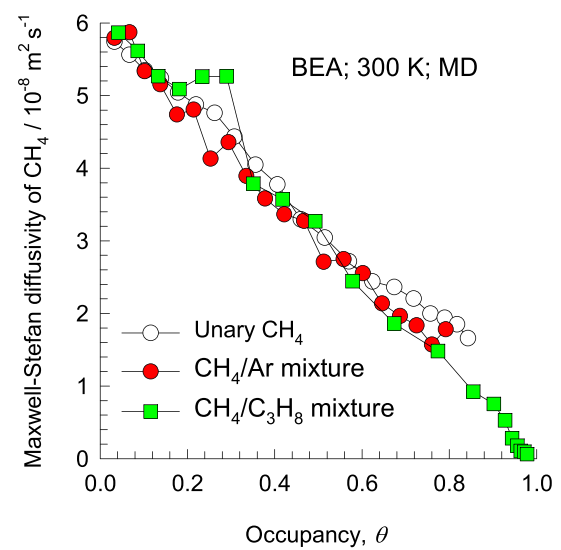

(f)

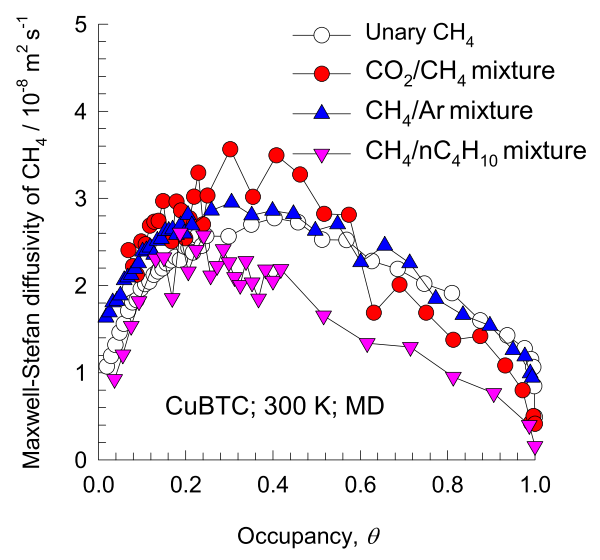

Figure 6. $\mathrm{M}-\mathrm{S}$ diffusivity, $\mathrm{D}_{i}$, of $\mathrm{CH}_{4}$-determined $\mathrm{MD}$ simulation data for diffusion of a variety of equimolar $\left(q_{1}=q_{2}\right)$ binary mixtures of $\mathrm{CH}_{4}$ and different partner species in (a) FAU (all silica), (b) NaY (48 Al), (c) NaX (86 Al), (d) BEA, (e) IRMOF-1, and (f) CuBTC. The $x$-axes represent the fractional $\theta$ defined by eq 15. Also shown in open symbols are the MD simulations of $\bigoplus_{i}$, for unary $\mathrm{CH}_{4}$ diffusion.

As illustration, Figure 3a presents IAST calculations of the adsorption potential plotted as a function of the molar loading for equimolar $\left(q_{1}=q_{2}\right)$ binary $\mathrm{CO}_{2}(1) / \mathrm{H}_{2}(2)$ mixtures in IRMOF-1 at $300 \mathrm{~K}$. For molar loadings lower than $25 \mathrm{~mol}$ $\mathrm{kg}^{-1}$, the value of $\frac{\pi A}{R T}$ is the same for each component as for the mixture. However, for molar loadings $>25 \mathrm{~mol} \mathrm{~kg}^{-1}$, the equality in the spreading pressures as demanded by eq 10 can only be achieved at different molar loadings of the unary components and the mixture. Indeed, if the MD data for the $\mathrm{M}-\mathrm{S}$ diffusivities are plotted as a function of $\frac{\pi A}{R T}$, the two sets of $\mathrm{M}-\mathrm{S}$ diffusivities are in good agreement with each other; see Figure $3 \mathrm{~b}$. Comparison of Figure $2 \mathrm{e}$ and $3 \mathrm{~b}$ underscores the need for a proper thermodynamic comparison yardstick for diffusivities.

From Figure $3 \mathrm{a}$, it is to be noted that the adsorption potential $\frac{\pi A}{R T}$ increases exponentially with the molar loading as the pores become increasingly saturated. Consequently, it is much more convenient in practice to compare the diffusivities on the basis of occupancy, $\theta$, defined by the following generalization of eq 12 


$$
\begin{aligned}
& \theta \equiv 1-\exp \left(-\frac{\pi A}{q_{\text {sat,mix }} R T}\right) ; \\
& q_{\text {sat,mix }}=\frac{x_{1}}{q_{1, \mathrm{~A}, \text { sat }}+q_{1, \mathrm{~B}, \mathrm{sat}}}+\frac{x_{2}}{q_{2, \mathrm{~A}, \mathrm{sat}}+q_{2, \mathrm{~B}, \mathrm{sat}}}
\end{aligned}
$$

Eq 15 degenerates to eq 12 for the 1-site Langmuir isotherm; the occupancy $\theta$ is to be viewed as a convenient, and practical, proxy for the spreading pressure, $\pi$.

\section{M-S DIFFUSIVITIES AS A FUNCTION OF OCCUPANCY}

The same set of MD simulation data in Figure 2 are plotted in Figure 4 with the occupancy $\theta$ as $x$-axes. In each of the six guest/host combinations, there is much closer agreement between the unary diffusivities and those characterizing mixture diffusion. Comparisons analogous to those presented in Figure 4 are presented in the Supporting Information for 70 different mixture/host combinations. The same conclusions drawn from Figure 4 hold in most, but not all, of these cases. There are two scenarios in which the $\mathrm{M}-\mathrm{S}$ diffusivity in the mixture deviates to a significant extent from the corresponding unary $\mathrm{M}-\mathrm{S}$ diffusivity. For water/methanol and water/ethanol diffusion in MFI and FAU zeolites, the $\mathrm{M}-\mathrm{S}$ diffusivities of either guest molecule in the mixture are significantly lower than the corresponding unary diffusivity because of the molecular clustering caused by hydrogen bonding. ${ }^{31}$ Similar departures between unary $\mathrm{M}-\mathrm{S}$ diffusivities and those characterizing mixture diffusion may also be expected for highly polar guest molecules such $\mathrm{CHN}, \mathrm{CH}_{2} \mathrm{~N}_{2}, \mathrm{CH}_{2} \mathrm{O}$, and $\mathrm{C}_{2} \mathrm{H}_{4} \mathrm{O}$. For diffusion of $\mathrm{CO}_{2}$-bearing mixtures in cage-type zeolites such as LTA, DDR, and ERI, $\mathrm{CO}_{2}$ gets preferentially, and strongly, adsorbed at the narrow windows of these zeolites, hindering the diffusion of partner molecules. As a consequence, the $\mathrm{M}-\mathrm{S}$ diffusivity of the partner molecule falls significantly below the corresponding value of the unary $M-S$ diffusivity. Detailed analysis and explanation of the hindering effects caused by segregated adsorption effects are provided in earlier works. ${ }^{32-34}$

A further, not fully appreciated, advantage of the $M-S$ formulation is that the $M-S$ diffusivity of any species in a mixture is also not influenced by the choice of the partner molecules. To illustrate this, Figure 5 provides data on the $\mathrm{M}-\mathrm{S}$ diffusivity of $\mathrm{CO}_{2}, \bigoplus_{i}$, determined from $\mathrm{MD}$ simulation data for diffusion of a variety of binary mixtures of $\mathrm{CO}_{2}$ and different partner species in six different host materials (MFI, FAU, LTA, CHA, IRMOF-1, CuBTC). For any host material, we note that the diffusivity of $\mathrm{CO}_{2}$ in a binary mixture is practically independent of the partner species. Furthermore, when compared at the same occupancy, $\theta$, the values of $\bigoplus_{i}$ are nearly the same in the mixture as those determined for unary diffusion, indicated by the open symbols in Figure 5. Similar conclusions hold for the $\mathrm{M}-\mathrm{S}$ diffusivity of $\mathrm{CH}_{4}$ in binary mixtures containing different partner species, in six different host materials (FAU, NaY, NaX, BEA, IRMOF-1, CuBTC); see Figure 6.

Figure 7 presents the data on the $\mathrm{M}-\mathrm{S}$ diffusivity, $\bigoplus_{i}$, of $\mathrm{Ar}$ determined from $\mathrm{MD}$ simulations for diffusion of a variety of binary mixtures of Ar and different partner species in MFI, FAU, and IRMOF-1. The M-S diffusivity of Ar is the same whether it diffuses on its own or in the presence of any other partner molecule. (a)

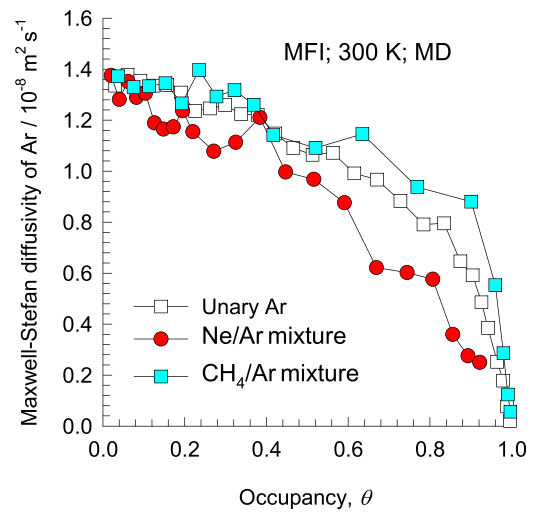

(b)

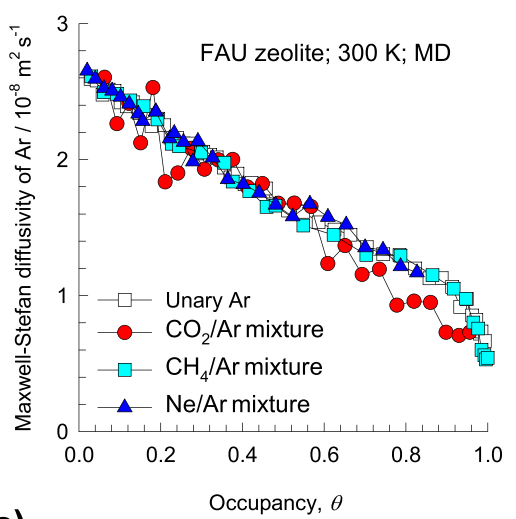

(c)

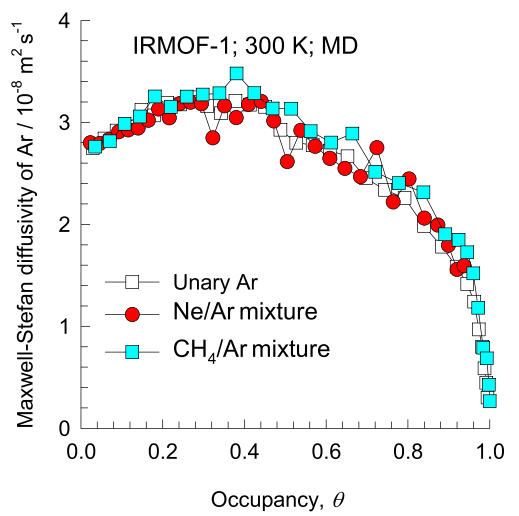

Figure 7. M-S diffusivity, $\bigoplus_{i}$, of Ar-determined MD simulation data for diffusion of a variety of equimolar $\left(q_{1}=q_{2}\right)$ binary mixtures of $\mathrm{Ar}$ and different partner species in (a) MFI, (b) FAU-Si, and (c) IRMOF-1. The $x$-axes represent the fractional $\theta$ defined by eq 15 . Also shown in open symbols are the MD simulations of $\bigoplus_{i}$, for unary Ar diffusion.

Use of the generalized definition of occupancy $\theta$ (determined using eq 15) as a comparison metric also allows a simpler description of the occupancy dependence of the M$S$ diffusivities; for example, the $\mathrm{M}-\mathrm{S}$ diffusivity of $\mathrm{CO}_{2}$ in MFI, FAU, and CHA (see Figure $5 \mathrm{a}, \mathrm{b}, \mathrm{d}$ ), $\mathrm{CH}_{4}$ in FAU, NaY, $\mathrm{NaX}$, and BEA zeolites (see Figure $6 \mathrm{a}-\mathrm{d}$ ), and Ar in FAU (see Figure $7 \mathrm{~b}$ ) conform reasonably well with a simple lattice model in which the hopping frequency of molecular jumps is proportional to the number of unoccupied sites.

$$
\mathrm{Ð}_{i}=\mathrm{Ð}_{i}(0)(1-\theta)
$$


(a)

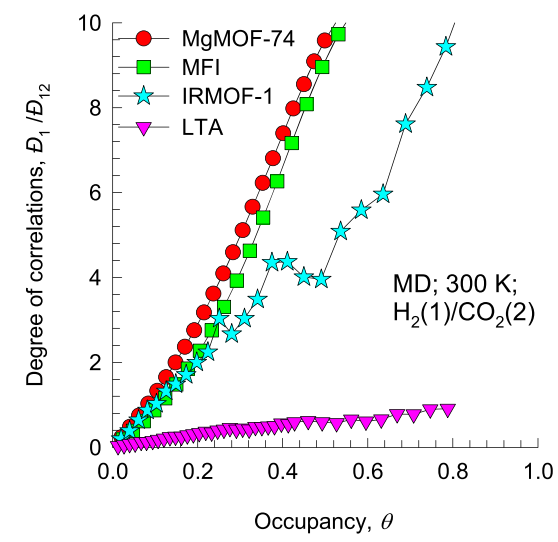

(c)

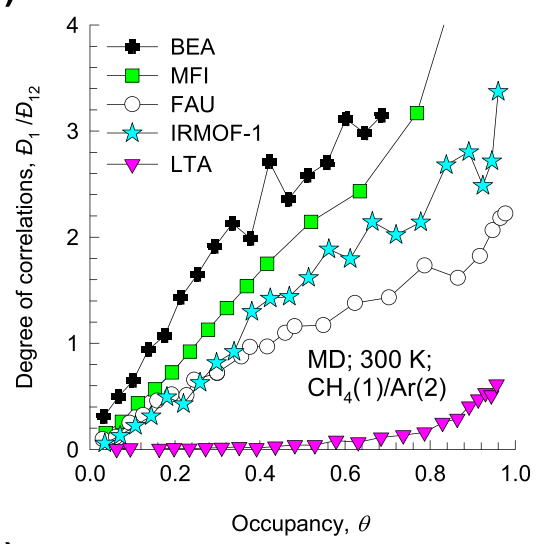

(e)

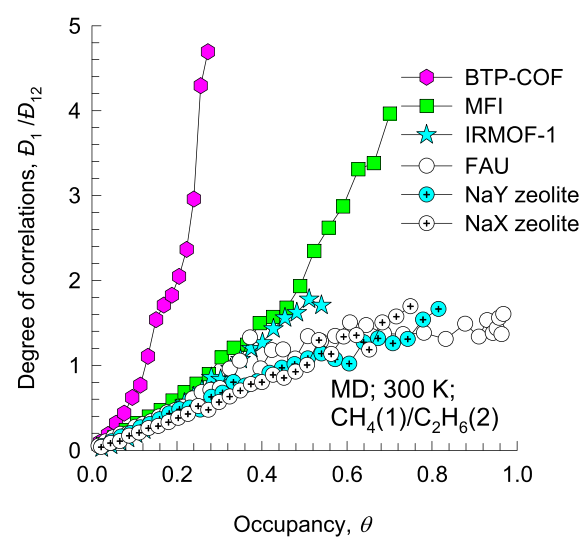

(b)

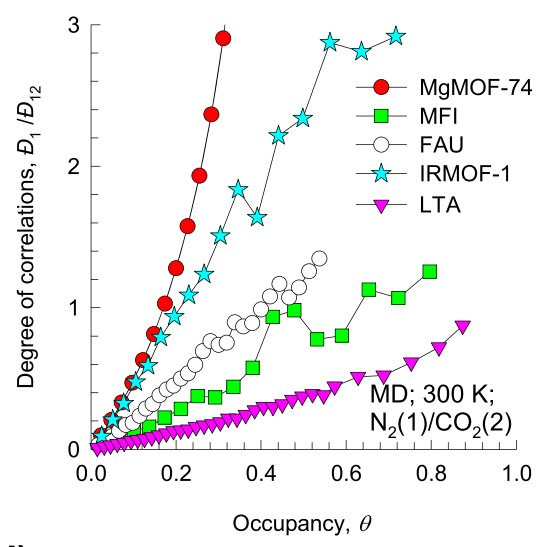

(d)

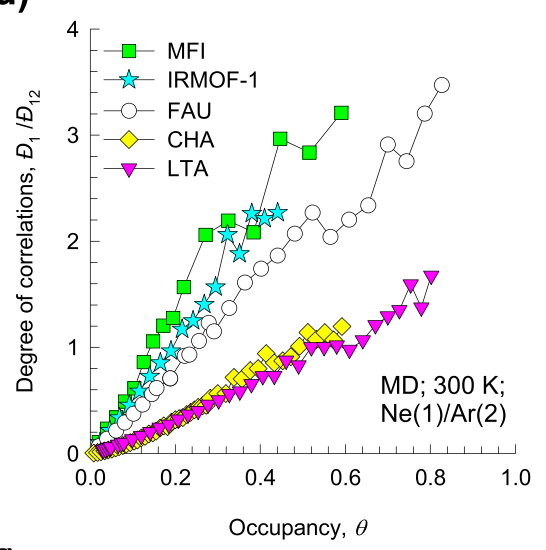

(f)

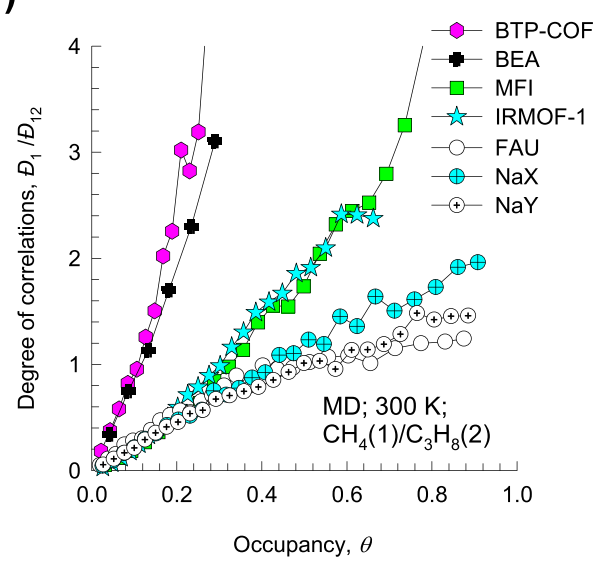

Figure 8. MD simulation data for the degree of correlations, $\oplus_{1} / \oplus_{12}$, for diffusion of equimolar $\left(q_{1}=q_{2}\right)$ binary mixtures $(\mathrm{a}) \mathrm{H}_{2} / \mathrm{CO}_{2},(\mathrm{~b}) \mathrm{N}_{2} /$ $\mathrm{CO}_{2}$, (c) $\mathrm{CH}_{4} / \mathrm{Ar}$, (d) $\mathrm{Ne} / \mathrm{Ar}$, (e) $\mathrm{CH}_{4} / \mathrm{C}_{2} \mathrm{H}_{6}$, and (f) $\mathrm{CH}_{4} / \mathrm{C}_{3} \mathrm{H}_{8}$ at $300 \mathrm{~K}$ in a variety of host materials. The $x$-axes represent the fractional $\theta$ defined by eq 15. Procedures for estimation of the degrees of correlation are discussed in Chapter 10 of the Supporting Information.

The success of the simple model in these cases is directly ascribable to the fact that the occupancy defined by eq 15 takes proper account of all of the isotherm characteristics, such as inflections, that influence diffusivities.

For the other guest/host combinations, the $\bigoplus_{i}$ versus $\theta$ dependences are more complicated and require models such as that of Reed and Ehrlich ${ }^{35}$ that account for moleculemolecule interactions. ${ }^{36-38}$

\section{DEGREE OF CORRELATIONS}

Figure 8 shows MD simulation data for the degree of correlations, $\bigoplus_{1} / \bigoplus_{12}$, for diffusion of equimolar binary mixtures $\mathrm{H}_{2} / \mathrm{CO}_{2}, \mathrm{~N}_{2} / \mathrm{CO}_{2}, \mathrm{CH}_{4} / \mathrm{Ar}, \mathrm{Ne} / \mathrm{Ar}, \mathrm{CH}_{4} / \mathrm{C}_{2} \mathrm{H}_{6}$, and $\mathrm{CH}_{4} / \mathrm{C}_{3} \mathrm{H}_{8}$ in a variety of host materials. For any guest/ host combination, $\bigoplus_{1} / \bigoplus_{12}$ is seen to increase linearly as the pore occupancy increases; correlation effects are enhanced as the micropores become increasingly occupied. The degree of correlations is weakest in cage-type structures such as CHA, DDR, ERI, and LTA that have narrow eight-ring windows in the 3.6-4.2 $\AA$ size range. In such structures, the windows allow the intercage hopping of only one molecule at any given instant of time; consequently, the jumps are practically uncorrelated. ${ }^{39}$ On the other hand, correlations are strongest in one-dimensional channel structures (e.g., BTP-COF, MgMOF-74, NiMOF-74), intersecting channels (e.g., MFI, 
BEA, ISV), and "open” structures (e.g., IRMOF-1, CuBTC, FAU, $\mathrm{NaY}, \mathrm{NaX}$ ) consisting of large cages separated by wide windows. $^{39}$ Procedures for estimation of the degree of correlations are provided in the Supporting Information.

\section{CONCLUSIONS}

Using the IAST theory of Myers and Prausnitz, ${ }^{24}$ a thermodynamically rigorous definition of the occupancy, $\theta$, has been derived (see eq 15), which is a convenient proxy for the spreading pressure, $\pi$. The $\mathrm{M}-\mathrm{S}$ diffusivity $\bigoplus_{i}$ of any component in the mixture has the same value as that for unary diffusion if the comparison is made at the same $\theta$. Compared at the same value of $\theta$, the $M-S$ diffusivity $\bigoplus_{i}$ of any component in a mixture does not depend on it partner species. The $\bigoplus_{i}$ versus $\theta$ dependence is amenable to simple interpretation using lattice-models such as that of Reed and Ehrlich. $^{35-38}$ The degree of correlations, $\bigoplus_{1} / \bigoplus_{12}$, exhibits a simple linear dependence on the occupancy $\theta$, implying that correlations become increasingly important as pore saturation conditions are approached.

\section{ASSOCIATED CONTENT}

\section{S Supporting Information}

The Supporting Information is available free of charge on the ACS Publications website at DOI: 10.1021/acsomega.8b02465.

structural details for zeolites and MOFs considered and analyzed in this article, CBMC simulation methodology, ${ }^{23,25,26} \mathrm{MD}$ simulation methodology, ${ }^{23}$ CBMC simulation data of the unary adsorption isotherms, along with dual-Langmuir-Freundlich data fits, detailed derivation of the IAST calculation procedures for the spreading pressure, and its proxy $\theta$, using the unary adsorption isotherms determined from CBMC simulations, $\mathrm{MD}$ simulation data sets for unary and binary mixture diffusion for each mixture/host combination (a total of 70 data sets), and procedures for estimation of the degrees of correlation for mixture diffusion (PDF)

\section{AUTHOR INFORMATION}

\section{Corresponding Author}

*E-mail: r.krishna@contact.uva.nl.

\section{ORCID $\odot$}

Rajamani Krishna: 0000-0002-4784-8530

Notes

The author declares no competing financial interest.

\section{ACKNOWLEDGMENTS}

The generous assistance of Dr. Jasper van Baten, AmsterCHEM, in performing the $\mathrm{CBMC}$ and $\mathrm{MD}$ simulations is gratefully acknowledged.

\section{NOMENCLATURE}

\section{Latin Alphabet}

A surface area per $\mathrm{kg}$ of framework, $\mathrm{m}^{2} \mathrm{~kg}^{-1}$

$b_{\mathrm{A}}$ dual-Langmuir-Freundlich constant for species $i$ at adsorption site $\mathrm{A}, \mathrm{Pa}^{-\nu}$

$b_{\mathrm{B}}$ dual-Langmuir-Freundlich constant for species $i$ at adsorption site $\mathrm{B}, \mathrm{Pa}^{-\nu}$

$\bigoplus_{i} \quad \mathrm{M}-\mathrm{S}$ diffusivity for molecule-wall interaction, $\mathrm{m}^{2} \mathrm{~s}^{-1}$ $\bigoplus_{i}(0) \quad M-S$ diffusivity at zero-loading, $\mathrm{m}^{2} \mathrm{~s}^{-1}$

$\bigoplus_{12} \quad M-S$ exchange coefficient for binary mixture, $\mathrm{m}^{2} \mathrm{~s}^{-1}$

$f_{i} \quad$ partial fugacity of species $i, \mathrm{~Pa}$

$f_{\mathrm{t}} \quad$ total fugacity of bulk fluid mixture, $\mathrm{Pa}$

$n$ number of species in the mixture, dimensionless

$N_{i} \quad$ molar flux of species $i$ with respect to framework, mol $\mathrm{m}^{-2} \mathrm{~s}^{-1}$

$P_{i}^{0} \quad$ sorption pressure, $\mathrm{Pa}$

$q_{i} \quad$ component molar loading of species $i, \mathrm{~mol} \mathrm{~kg}^{-1}$

$q_{i, \text { sat }}$ molar loading of species $i$ at saturation, $\mathrm{mol} \mathrm{kg}^{-1}$

$q_{\mathrm{t}} \quad$ total molar loading in mixture, $\mathrm{mol} \mathrm{kg}^{-1}$

$R \quad$ gas constant, $8.314 \mathrm{~J} \mathrm{~mol}^{-1} \mathrm{~K}^{-1}$

$T$ absolute temperature, $\mathrm{K}$

$x_{i}$ mole fraction of species $i$ in adsorbed phase, dimensionless

$z \quad$ distance coordinate, $\mathrm{m}$

\section{Greek Alphabet}

$[\Lambda]$ matrix of $\mathrm{M}-\mathrm{S}$ diffusivities, $\mathrm{m}^{2} \mathrm{~s}^{-1}$

$\mu_{i} \quad$ molar chemical potential of component $i, \mathrm{~J} \mathrm{~mol}^{-1}$

$\pi$ spreading pressure, $\mathrm{N} \mathrm{m}^{-1}$

$\theta_{i}$ fractional occupancy of component $i$, dimensionless

$\nu$ exponent in dual-Langmuir-Freundlich isotherm, dimensionless

$\rho$ framework density, $\mathrm{kg} \mathrm{m}^{-3}$

\section{Subscripts}

1 referring to component 1

2 referring to component 2

$i$ referring to component $i$

$t$ referring to total mixture

sat referring to saturation conditions

\section{REFERENCES}

(1) Kärger, J.; Ruthven, D. M.; Theodorou, D. N. Diffusion in Nanoporous Materials; Wiley-VCH: Weinheim, 2012.

(2) Keil, F. J.; Krishna, R.; Coppens, M.-O. Modeling of diffusion in zeolites. Rev. Chem. Eng. 2000, 16, 71-197.

(3) Ruthven, D. M. Principles of Adsorption and Adsorption Processes; John Wiley: New York, 1984.

(4) Caro, J.; Noack, M. Zeolite membranes - Recent Developments and Progress. Microporous Mesoporous Mater. 2008, 115, 215-233.

(5) Caro, J. Are MOF membranes better in gas separation than those made of zeolites? Curr. Opin. Chem. Eng. 2011, 1, 77-83.

(6) Krishna, R. The Maxwell-Stefan Description of Mixture Diffusion in Nanoporous Crystalline Materials. Microporous Mesoporous Mater. 2014, 185, 30-50.

(7) Krishna, R. Describing the Diffusion of Guest Molecules inside Porous Structures. J. Phys. Chem. C 2009, 113, 19756-19781.

(8) Krishna, R. Methodologies for Screening and Selection of Crystalline Microporous Materials in Mixture Separations. Sep. Purif. Technol. 2018, 194, 281-300.

(9) Krishna, R. Diffusion in Porous Crystalline Materials. Chem. Soc. Rev. 2012, 41, 3099-3118.

(10) Hansen, N.; Krishna, R.; van Baten, J. M.; Bell, A. T.; Keil, F. J. Analysis of Diffusion Limitation in the Alkylation of Benzene over $\mathrm{H}$ ZSM-5 by Combining Quantum Chemical Calculations, Molecular Simulations, and a Continuum Approach. J. Phys. Chem. C 2009, 113, 235-246.

(11) Hansen, N.; Krishna, R.; van Baten, J. M.; Bell, A. T.; Keil, F. J. Reactor simulation of benzene ethylation and ethane dehydrogenation catalyzed by ZSM-5: A multiscale approach. Chem. Eng. Sci. 2010, 65, 2472-2480.

(12) Krishna, R.; Baur, R.; van Baten, J. M. Highlighting Diffusional Coupling Effects in Zeolite Catalyzed Reactions by Combining the Maxwell-Stefan and Langmuir-Hinshelwood Formulations. React. Chem. Eng. 2017, 2, 324-336. 
(13) Krishna, R. Methodologies for Evaluation of Metal-Organic Frameworks in Separation Applications. RSC Adv. 2015, 5, 5226952295 .

(14) Ruthven, D. M.; Farooq, S.; Knaebel, K. S. Pressure Swing Adsorption; VCH Publishers: New York, 1994.

(15) Yang, R. T. Gas Separation by Adsorption Processes; Butterworth: Boston, 1987.

(16) Yang, R. T. Adsorbents: Fundamentals and Applications; John Wiley \& Sons, Inc.: Hoboken, New Jersey, 2003.

(17) Krishna, R. Tracing the Origins of Transient Overshoots for Binary Mixture Diffusion in Microporous Crystalline Materials. Phys. Chem. Chem. Phys. 2016, 18, 15482-15495.

(18) Krishna, R. A Maxwell-Stefan-Glueckauf Description of Transient Mixture Uptake in Microporous Adsorbents. Sep. Purif. Technol. 2018, 191, 392-399.

(19) Krishna, R. Using the Maxwell-Stefan formulation for highlighting the influence of interspecies (1-2) friction on binary mixture permeation across microporous and polymeric membranes. J. Membr. Sci. 2017, 540, 261-276.

(20) Bux, H.; Chmelik, C.; Krishna, R.; Caro, J. Ethene/Ethane Separation by the MOF Membrane ZIF-8: Molecular Correlation of Permeation, Adsorption, Diffusion. J. Membr. Sci. 2011, 369, 284289.

(21) Bux, H.; Chmelik, C.; van Baten, J. M.; Krishna, R.; Caro, J. Novel MOF-Membrane for Molecular Sieving Predicted by IRDiffusion Studies and Molecular Modeling. Adv. Mater. 2010, 22, 4741-4743.

(22) Krishna, R.; van Baten, J. M. Describing Mixture Diffusion in Microporous Materials under Conditions of Pore Saturation. J. Phys. Chem. C 2010, 114, 11557-11563.

(23) Frenkel, D.; Smit, B. Understanding Molecular Simulations: From Algorithms to Applications, 2nd ed.; Academic Press: San Diego, 2002.

(24) Myers, A. L.; Prausnitz, J. M. Thermodynamics of mixed-gas adsorption. AIChE J. 1965, 11, 121-127.

(25) Vlugt, T. J. H.; Krishna, R.; Smit, B. Molecular Simulations of Adsorption Isotherms for Linear and Branched Alkanes and Their Mixtures in Silicalite. J. Phys. Chem. B 1999, 103, 1102-1118.

(26) Dubbeldam, D.; Calero, S.; Vlugt, T. J. H.; Krishna, R.; Maesen, T. L. M.; Smit, B. United Atom Force Field for Alkanes in Nanoporous Materials. J. Phys. Chem. B 2004, 108, 12301-12313.

(27) Krishna, R.; van Baten, J. M.; Baur, R. Highlighting the origins and consequences of thermodynamic non-idealities in mixture separations using zeolites and metal-organic frameworks. Microporous Mesoporous Mater. 2018, 267, 274-292.

(28) Krishna, R.; van Baten, J. M. Investigating the Non-idealities in Adsorption of $\mathrm{CO}_{2}$-bearing Mixtures in Cation-exchanged Zeolites. Sep. Purif. Technol. 2018, 206, 208-217.

(29) Siperstein, F. R.; Myers, A. L. Mixed-Gas Adsorption. AIChE J. 2001, 47, 1141-1159.

(30) García-Pérez, E.; Parra, J. B.; Ania, C. O.; García-Sánchez, A.; van Baten, J. M.; Krishna, R.; Dubbeldam, D.; Calero, S. A computational study of $\mathrm{CO}_{2}, \mathrm{~N}_{2}$ and $\mathrm{CH}_{4}$ adsorption in zeolites. Adsorption 2007, 13, 469-476.

(31) Krishna, R.; van Baten, J. M. Hydrogen Bonding Effects in Adsorption of Water-Alcohol Mixtures in Zeolites and the Consequences for the Characteristics of the Maxwell-Stefan Diffusivities. Langmuir 2010, 26, 10854-10867.

(32) Krishna, R.; van Baten, J. M. Segregation effects in adsorption of $\mathrm{CO}_{2}$ containing mixtures and their consequences for separation selectivities in cage-type zeolites. Sep. Purif. Technol. 2008, 61, 414423.

(33) Krishna, R, van Baten, J. M. Onsager coefficients for binary mixture diffusion in nanopores. Chem. Eng. Sci. 2008, 63, 31203140.

(34) Krishna, R.; van Baten, J. M. Influence of segregated adsorption on mixture diffusion in DDR zeolite. Chem. Phys. Lett. 2007, 446, 344-349.
(35) Reed, D. A.; Ehrlich, G. Surface diffusion, atomic jump rates and thermodynamics. Surf. Sci. 1981, 102, 588-609.

(36) Krishna, R.; Paschek, D.; Baur, R. Modeling the occupancy dependence of diffusivities in zeolites. Microporous Mesoporous Mater. 2004, 76, 233-246.

(37) Krishna, R.; van Baten, J. M. A molecular dynamics investigation of a variety of influences of temperature on diffusion in zeolites. Microporous Mesoporous Mater. 2009, 125, 126-134.

(38) Krishna, R. The Maxwell-Stefan Description of Mixture Permeation across Nanoporous Graphene Membranes. Chem. Eng. Res. Des. 2018, 133, 316-325.

(39) Krishna, R.; van Baten, J. M. Investigating the Influence of Diffusional Coupling on Mixture Permeation across Porous Membranes. J. Membr. Sci. 2013, 430, 113-128. 